\title{
0 kãchi no MAE/UFPR: sobre uma experiência de curadoria compartilhada
}

Edilene Coffaci de Lima

(UFPR)

A experiência de curadoria compartilhada que irei apresentar ${ }^{1}$ é bastante recente, foi concebida e realizada em abril de 2015 e resultou na exposição que ocupou por dez meses parte do prédio histórico do Museu de Arqueologia e Etnologia da UFPR (MAE/UFPR), em Paranaguá2. Nela foram apresentados os kãchi, i.e., o jogo de barbante, que chamamos de cama-de-gato, que realizam os Katukina (atuais Noke Kuin), um povo de língua pano, habitante de duas terras indígenas no estado do Acre, entre os quais iniciei trabalhos de pesquisa no início da década de 1990.

A concepção toda da exposição partilhei com Mame (Nivaldo) e seu filho Wisi (Fábio). ${ }^{3}$ Assumirei aqui certo tom memorialista, isso se deve menos a uma preferência pessoal que ao fato de que faço desse artigo um registro de uma experiência que não foi previamente calculada, arranjada, mas que, mesmo assim, produziu resultados importantes para se pensar nos modos como realizamos nossa prática profissional. Adiante detalharei como foi montada a coleção de kãchi exposta no MAE. De todo modo, tanto para falar dos kãchi quanto para falar da forma como foi concebida e partilhada a curadoria, tive de recorrer a lembranças pessoais, algumas bem recuadas no tempo. No presente, a experiência passada, vivida em campo, foi fundamental para que pudesse conduzir o trabalho que resultou em experimentações e importantes resultados para todos que se engajaram em sua realização.

Assim, para começar, parece-me importante mencionar brevemente que a decisão de trabalhar os kãchi no MAE com Mame não passou por maiores negociações políticas, foi uma decisão sobretudo minha, em virtude do fato de que foi na casa da mãe dele, de Mampu, e entre seus familiares que as camas-de-gato me foram apresentadas. Sustentei assim a decisão baseando-me em nossas antigas relações e na retribuição que gostaria de lhes oferecer em virtude dos períodos prolongados de hospedagem nos quais me acolheram, cuidaram e partilharam suas vidas. Até onde posso saber, tal decisão e a realização da exposição não causou quaisquer contestações por parte das lideranças políticas ${ }^{4}$. 
Antes de iniciar, cabe ainda dizer que não fiz uma busca bibliográfica exaustiva sobre as camas-de-gato entre povos indígenas nas terras baixas sul-americanas. De todo modo, acabei reunindo algumas informações. Assim, é possível saber que provavelmente o primeiro registro de jogos de fio entre grupo indígenas localizados no Brasil é o de Koch-Grümberg (2005) ${ }^{5}$, a partir do que pôde conhecer em sua viagem no noroeste amazônico, no início do século passado. No mais, sei apenas, baseando-me numa rápida pesquisa na internet, que há registros da realização de jogos-de-barbante, ou camas-de-gato, também entre povos do Xingu, como os Kalapalo, e entre os Wapixana, localizados em Roraima. No site do PIB Mirim, do Instituto Socioambiental, são disponibilizadas algumas informações e um pequeno filme de camas-de-gato entre os Kalapalo 6 . Desconheço referências bibliográficas sobre a existência de camas-de-gato entre outros povos de língua pano. Tenho apenas a informação pessoal (2015) da linguista Eliane Camargo, que viu algumas entre os Kaxinawá do lado peruano. Dedê Maia, indigenista acreana, que atua entre os índios do Acre desde meados da década de 1970 e conhece os moradores das diversas terras indígenas do estado, afirmou-me jamais tê-las visto entre os povos que visitou (informação pessoal 2014).

Sem que seja o caso de discorrer aqui sobre os registros existentes ${ }^{7}$, os jogos de barbante são bastante difundidos ao redor do mundo (Victor 1937; Averkieva \& Sherman 1992; Martínez Castellote 1996; Guevara 2011; Vidaurrázagua 2012; Valendriessche 2014), mas não buscarei, num arroubo difusionista, especular sobre suas origens. Há quem diga (Averkieva \& Sherman 1992:25) mesmo que nenhum jogo se distribui tão amplamente no globo quanto os jogos de barbante ou jogos de fios - ou camas-de-gato, em português; jeu de ficelle, em francês; string figures, em inglês. Sherman (1992:25) apresenta uma tabela na introdução do livro que publicou com J. Averkieva e oferece o número de formas que vários grupos indígenas distribuídos ao redor do mundo conseguem realizar. Embora não tenha realizado uma pesquisa minuciosa sobre a quantidade de formas que os Katukina realizam, o número que alcancei - aproximadamente 35 - não fica distante da média da maior parte dos grupos que consta na listagem que apresenta.

Para encerrar esta introdução, destaco que entre os Rapa Nui, moradores da llha de Páscoa, no Oceano Pacífico, a realização de kai kai, como chamam suas camas-de-gato, se faz conjugada com a recitação de versos, conforme escreveu Tamara Vidaurrázagua (2012). A autora recusa entender as camas-de-gato como "jogos" dado o fato, entre outras coisas, de que não há qualquer disputa ou desafio envolvido em suas elaborações. Mas, sobretudo, tal recusa se dá porque tal apreciação dos fios simetricamente alinhados como "meros jogos", revela, nos termos da autora, nossa incapacidade de compreendê-los genuinamente, pois que reduz o entrelaçamento do barbante a uma perspectiva eurocêntrica, incapaz de alcançar o entendimento de tal "prática transcendental"8. A maneira como Vidaurrázagua (idem) apresenta as camas-de-gato dos Rapanui parece assemelhar-se apenas superficialmente aos Katukina que tanto não os executam conjugados com a recitação de versos quanto não limitam sua realização a pessoas específicas. Ao contrário, como detalharei adiante, entre os Katukina, a todos, desde a infância, é permitido o aprendizado dos kãchi, e sua realização alcança maior sofisticação na vida adulta, com a realização de um número maior e mais complexo de formas. Embora não haja uma disputa explícita entre aqueles que conseguem fazer as manobras que resultam nos kãchi, é notório que há pessoas que sabem mais que outras e 
os primeiros são admirados por suas habilidades, que não resultam em quaisquer vantagens mensuráveis. Assim, diferentemente da autora mencionada, insistirei em tratar aqui os kãchi enquanto um tipo de "jogo", por um duplo motivo: a maior parte dos autores que nos legaram registros sobre as camas-de-gato assim o fazem; e também porque, ao menos entre os Katukina, sua realização é recreativa e visa o entretenimento.

Feito esse breve preâmbulo, cabe apresentar o jogo de barbante dos Katukina. Pois bem, kãchi é um jogo de barbante que resulta em formas diversas, boa parte delas com motivos que fazem referência às anatomias animal e vegetal. Joga-se sozinho, entrelaçando os fios entre os dedos das mãos, algumas vezes sendo preciso servir-se também da boca (lábios e dentes) e dos pés para alcançar a forma desejada, como registrado também entre os Mapuche (Guevara 2011). Pouco a pouco, diversas formas abstratamente se revelam: tae teshe (pé de urubu), rono mapu (cabeça de cobra), kãchi pei (asa de morcego) e tao pei (folha de paxiubão), entre outras. Tenho conhecimento apenas de um kãchi que exige a presença de duas pessoas para ser realizado: trata-se exatamente do senoti (serrote), apresentado no filme ${ }^{9}$ que acompanhava a exposição no MAE. Há também um kãchi no qual se faz uso das mãos e dos pés para ser realizado: trata-se do shevi (vagina) ${ }^{10}$.

Para fazer um kãchi basta dispor de um longo pedaço de barbante, amarrado em suas extremidades, e movimentá-lo de forma calculada. Revelada a forma, desfaz-se o barbante e reinicia-se o jogo. São normalmente pessoas co-residentes que se entregam à ludicidade em situações de retiro doméstico, quando as pessoas permanecem na intimidade de suas casas. Crianças dedicam-se ao kãchi também em meio a outras brincadeiras. Trata-se de um jogo infantil, mas é também mais do que isso, pois envolve uma sociabilidade específica, entrelaçando não apenas fios, mas também pessoas de diferentes gerações. Em tal emaranhado, jovens e adultos dominam um repertório maior de motivos ou formas finais, e são aqueles que os ensinam às crianças, ajudando-as a desenvolverem a habilidade no jogo. Paradoxalmente, para que possa continuar sendo feito, o kãchi depende de ser desfeito inúmeras vezes.

A experiência de curadoria compartilhada foi nova para mim em múltiplos sentidos. A novidade devia-se, entre outras coisas, ao fato de que antes sequer havia realizado uma curadoria individual ou solitária, digamos assim... Mais inédita ainda foi a experiência para Mame e Wisi, que nunca tinham antes entrado em um museu. Até onde sei, a experiência foi também marcada pela novidade para a equipe do MAE/UFPR que não tinha antes trabalhado na montagem de uma exposição com índios realizadores dos objetos exibidos. Em meio a tanto ineditismo, a experiência foi, se assim posso resumir, enriquecedora. Como não poderia deixar de ser, procedemos por ensaio e erro, e aprendemos muitas coisas ao mesmo tempo. Partilhamos o mesmo caminho, mas seguramente cada um o apreendeu de distintas formas.

Na verdade, sem querer cometer um perjuro, acredito que cometemos apenas um erro grave, que abordarei adiante e sobre o qual assumo plena responsabilidade. Minha nula experiência com curadoria não o explica, 
sobretudo se considerada minha larga experiência com os Katukina - na qual confiei, mas que foi insuficiente para impedir alguma distração. Seja como for, acabou por tratar-se de um "erro instrutivo", como detalharei adiante.

Antes de me alongar e discorrer sobre a co-curadoria e a montagem da exposição, é preciso saber que ela é resultado de uma convivência bastante longa ${ }^{11}$ com os Katukina, moradores de duas Terras Indígenas (nos rios Campinas e Gregório) no Acre. Quero deixar claro, no entanto, que ela revela não só o jogo de barbantes, o kãchi, mas também as relações entre as pessoas que acabaram por se misturar e a aprender a fazer determinadas coisas juntas, partilhando seus espaços e seus próprios conceitos. A montagem da exposição pode ser também uma boa metáfora para o modo de se fazer Antropologia, ou seja, algo que se faz muito lentamente, artesanalmente, com ensaios e erros. A pesquisa antropológica, embora evidentemente exija um esquema, um projeto, não pode se enclausurar nele, sob o risco de nos fixarmos exageradamente num foco, desviando o olhar do entorno - e o entorno não pode, de forma alguma, ser desprezado.

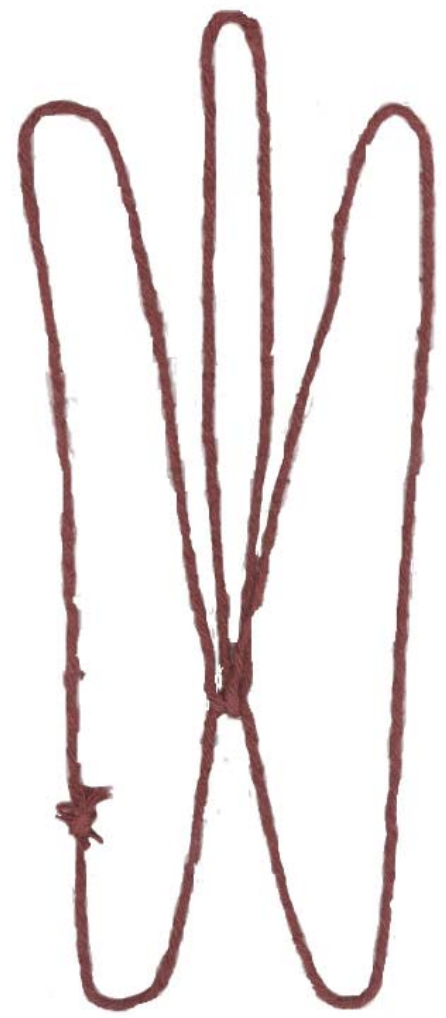

Figura 1: txeshe tae (pé de urubu)

Falo isso por que cheguei aos Katukina em 1991, quando fazia o mestrado. Não conheci o kãchi imediatamente, algo que só aconteceu em 1997, já na realização do trabalho de campo do doutorado. Feitas as contas, o kãchi chegou ao meu conhecimento apenas seis anos após eu frequentar as aldeias katukina quase que anualmente, passando com eles períodos relativamente prolongados de 4-6 meses. Estava na casa da mãe de Mame, a Mampu (também conhecida como Dona Alzira), e, num dia chuvoso, "sem nada para fazer" e, por isso, impedida de me deslocar às outras casas, um sobrinho do Mame, Rai, que era à época uma criança de 8-10 anos, resolveu de repente pegar um cordão e me mostrar um kãchi ${ }^{12}$. Claro que achei suas manobras com a mão e os resultados produzidos muito divertidos. No restante daquela temporada em campo, imagino que aprendi a fazer uns quatro ou cinco kãchi e imediatamente notei que aqueles que realizavam os Katukina eram diferentes das "camas-de-gato" que tinha aprendido na infância. Uma das principais diferenças era que Rai jogava sozinho, não em dupla, mostrando-me as formas/motivos finais que conseguia realizar. Pouco a pouco, nos dias que se seguiram, a meu pedido, mais pessoas foram se juntando e fazendo outras formas, feitas e desfeitas repetidas vezes. À medida em que conhecia o repertório de kãchis que as pessoas podem realizar, passei a lamentar que não tinha como "guardar", dado que o barbante era sempre feito e desfeito, não tinha ideia de como montar uma coleção. Foi então que meu marido, Eduardo, que permaneceu por um breve período me acompanhando em campo, teve a ideia de 
fazer a coleção colando as formas finais num papel A4. Foram então os materiais usados para formar a coleção: papel A4, cola branca e barbante.

A simplicidade dos materiais utilizados para montar a coleção expunha também sua limitação, pois, fixando a forma no papel, perdia completamente o processo de sua realização. De qualquer forma, era o possível (não tinha uma filmadora por perto) e assim montei a modesta coleção que apresentamos na exposição do MAE, toda emoldurada. A presença de Mame e Wisi no MAE veio somar-se ao esforço de não fixá-la excessivamente, permitindo registros fílmicos que pretendem resguardar os movimentos que permitem sua própria constituição.

Salvo engano meu, foram expostos no MAE 36 kãchi. Certamente as formas colecionadas não esgotam o repertório completo e nem se pretende exaustiva. Há formas expostas que Mame e Wisi não sabem fazer. Do mesmo modo, Mame e Wisi chegaram a Curitiba e fizeram formas que desconhecia... Mame, preparando-se para a exposição, passou a pesquisar o kãchi em sua aldeia e soube que Pochá, um velho senhor, pode realizar mais de 25 formas e seu repertório não é exaustivo, ainda que seja o maior conhecedor.

Resumindo o percurso que resultou na exposição, o fato é que a coleção feita em campo, em 1997, e exposta no MAE, em Paranaguá, ficou guardada por 18 anos! Sem a pretensão de que as coisas fossem assim, a coleção de kãchi feita em campo só se tornou pública quando alcançou sua maturidade! Nos nossos termos, mas talvez também (involuntariamente) nos termos katukina, para quem os saberes devem sempre ser guardados, amadurecidos, antes de serem partilhados. Passa-se assim, por exemplo, com os cantos de cura (shoiti) e com o uso do kampô (Lima 2012).

Sem querer me estender excessivamente e voltando então à antropologia e ao seu método, resta a breve lição de que devemos tentar fazer as coisas sem pressa, mas com bastante atenção e comprometimento. Tudo à nossa volta pode ganhar novas oportunidades, novos sentidos. É a atenção aos pequenos detalhes e às diferentes formas de estar no mundo que constitui nosso patrimônio - palavra bem sugestiva quando se expõe uma efêmera coleção dentro de uma construção do séc. XVIII, sólida o suficiente para durar até hoje, como é o prédio histórico do MAE, um ex-colégio jesuíta, outrora também um forte militar.

Paradoxalmente, na sólida construção, tombada pelo patrimônio histórico nacional ainda em 1972 (Kersten 2000), foram expostas coisas como os kãchi, que só durarão se forem sempre desfeitos e refeitos. Sem esquecer que, nem jesuítas nem militares, agora os índios podiam também dispor daquele belo e imponente espaço.

Tudo se passava como se as formas fixas da exposição - fossem os kãchi emoldurados, escaneados (como nas imagens deste artigo) ou fotografados - arriscassem subverter o próprio kãchi, que para existir exige continuar em movimento, sendo feito e desfeito indeterminadamente... Especulando um tanto, parece-me possível aproximar o risco de tornar o kãchi algo excessivamente rígido a partir da realização da exposição - como um de seus efeitos -, àquela preocupação mencionada por Dominique Gallois (1994) sobre o risco de "congelamento" dos mitos imposto pela forma escrita. Embora não fosse a escrita que estivesse em questão, as formas emoldurada e fotografada do kãchi, seus suportes fixos, também o "congelam", tornando-o "endurecido", não dão conta do entrelaçamento do barbante, subtraindo justamente o processo de elaboração de sua forma. No fim das contas, as concepções de 
patrimônio material e imaterial tocavam-se e tudo se passava como se estivéssemos - e estávamos de certa forma - materializando um saber plenamente imaterial. Seja como for, no compartilhamento da curadoria, é inevitável dizer que tal preocupação parecia ser mais minha que de Mame e Wisi.

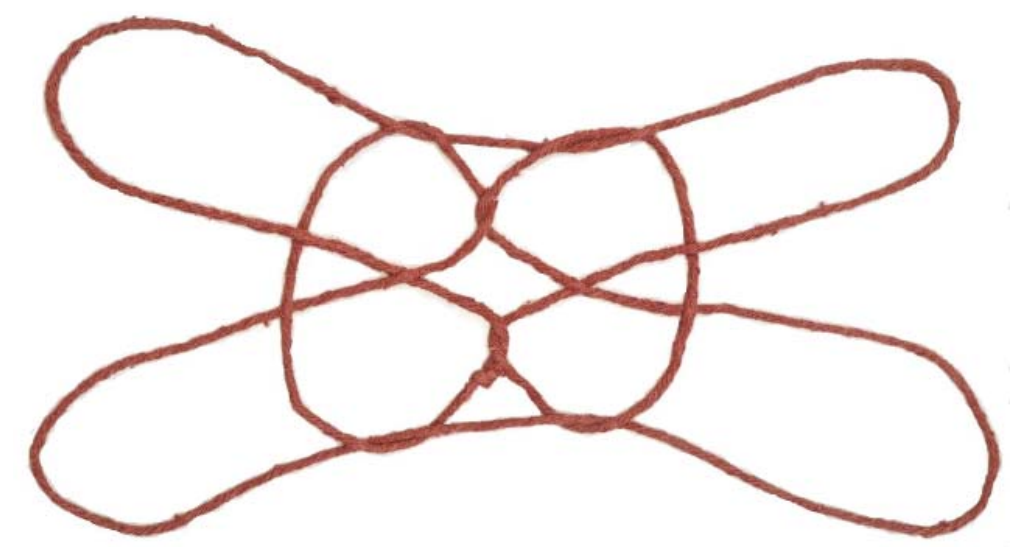

Figura 2: Txaki shao (osso de txaki - uma espécie de rã)

Para tentar contornar esse problema, para buscar expor algo que não é feito para permanecer, diferentemente dos nossos monumentos, é que realizamos o pequeno filme que acompanha a exposição. Nele apresentamos quatro kãchi justamente para mostrar esse contínuo fazer e desfazer, sem fixá-lo duramente, condição da permanência do objeto. Nele é possível ver também a complexidade dos cálculos que o realizador do kãchi precisa ter memorizado para alcançar seu intento. No MAE o filme foi projetado numa pequena sala anexa à exposição para que os visitantes pudessem ter alguma ideia do processo de elaboração das formas que acabaram de ver, quem sabe assim permitindo também que as conhecessem melhor. A tomada final no filme, aliás, imaginei-a ingênua e repentinamente, quando encerrávamos a filmagem, tentando dar forma à contradição entre a maleabilidade do barbante e a rigidez das pedras do prédio que acolhe a exposição. Ao dispor um kãchi sobre o chão, nas pedras, achei que o barbante poderia sugerir a efemeridade de um e a perenidade do outro ou a maleabilidade de um e a rigidez do outro - ambos podendo oferecer alguma ideia das concepções de patrimônio, material e imaterial, tão díspares e simultâneas, dispostas em um mesmo lugar.

A atenção à efemeridade da forma marcou uma preocupação que poderia parecer ser apenas minha, conforme mencionei antes, mas que se revelou também nas preocupações de Mame, meu principal interlocutor na concepção e na montagem da exposição. É certo que sua preocupação seguia um percurso conceitual que lhe é próprio, e não necessariamente coincidente com o meu. Seja como for, ainda que por caminhos distintos, a cocuradoria fazia sobressair sua face dialógica. Aqui chegamos então ao erro - ou ao mal-entendido, como prefiro - que mencionei no início. 
Antes que Mame tivesse chegado a Curitiba, começamos a imaginar - eu e a equipe do MAE, especialmente Márcia Rosato (a diretora) e Ana Luísa Mello (a museóloga) - alternativas para a exposição. Além da coleção que havia montado em 1997 e que seria emoldurada, imaginamos, a partir da sugestão da museóloga, fazer moldes de gesso com as mãos e braços de Mame para que ele pudesse fazer novas camas-de-gato e expô-las entre os seus dedos.

Logo que Mame chegou a Curitiba propus primeiramente, por achar mais prudente, apresentá-lo ao Museu, mostrar toda a Reserva Técnica (RT), antes de iniciar o trabalho. Sabendo que Mame e Wisi jamais tinham estado em um Museu, apresentamos-lhes toda a RT no primeiro dia. A única atividade seria essa para que pudessem ficar à vontade, conhecer o acervo e também as pessoas com as quais trabalhariam nos próximos dias. Exímio artesão, sobretudo após o acidente ofídico, durante uma pescaria em 2011, que resultou na amputação de parte de sua perna esquerda, Mame queria ver cada detalhe dos objetos que apresentávamos na RT, queria tocá-los e imaginar como haviam sido confeccionados. Isso se deu sobretudo na parte relativa a arte plumária, quando quis ver especialmente a amarração das penas nos diversos cocares. Enquanto nos demorávamos entre as penas, não resisti e, conhecendo a concepção nativa que valoriza a cópia e não necessariamente a originalidade e a autoria, perguntei se estava "copiando". Mame, sem qualquer pudor, admitiu publicamente que $\operatorname{sim}^{13}$.

Mais tarde, já em minha casa, onde ficou hospedado por três semanas, Mame revelou-me sua admiração com o acervo do MAE ao me perguntar: "quer dizer que aquelas coisas estão lá (na RT) há mais de 50 anos?". Apresentou-se, assim, uma pista de um certo desconforto com o armazenamento, por tempo indeterminado dos objetos, quando lhe dei uma resposta positiva.

No dia seguinte veio a prova de fogo. Com o auxílio de Mariana Zarpellon, aluna da graduação em Ciências Sociais que fora por mim convidada a integrar a equipe para auxiliar com as filmagens e fotografias, mas que logo na primeira reunião revelara outros talentos, decidimos fazer os moldes em gesso das mãos e braços de Mame, que serviriam como suportes para a exposição dos kãchis. Suas mãos, moldadas em gesso, serviriam para expor os kãchis, deixando os barbantes expostos e bem arranjados entre seus dedos.

Antes de fazermos alguns pares de suas mãos, que serviriam como suportes expográficos, Mariana sugeriu que fizéssemos um pequeno teste para ver como ficaria. Foi providencial o teste. Explico.

Mame se dispôs-se à moldagem sem problemas, enquanto o restante da equipe documentava o procedimento - fotografava e filmava, assim como Wisi. Não houve qualquer problema. Transcorrido um certo tempo, quando estava seco o gesso e pronto para ser revelado o molde, apareceu o problema. À medida em que Mariana tirava a réplica da mão de Mame do vasilhame em que foi modelado, seu semblante de surpresa revelava-se negativo. Diante de várias pessoas que acompanhavam a cena, Mame tentava ocultar seu desconforto, mas ficou claro para mim que a experiência não fora boa. Ali mesmo, imediatamente, informei-lhe que se não havia gostado poderia nos dizer e desprezaríamos o plano que havíamos feito. Ele desconversou. Como o desconforto de Mame parecia-me evidente, chamei Márcia Rosato e Laura Pérez - diretora e vice-diretora do MAE - e comuniquei que a modelagem estava cancelada, que não usaríamos mais os moldes em gesso, que deveriam ser feitos a partir das mãos e dos 
braços de Mame, como suporte. Deveria imaginar outra forma de expor os kãchi com a museóloga - o que acabou sendo feito usando apenas uma vitrine e pregos para manter esticado o barbante do kãchi. Uma alternativa, aliás, na qual Mame se engajou bastante voluntariamente, tomando o martelo de minha mão, quando notou minha falta de habilidade com a ferramenta, e fixando os pregos para expor suas realizações.

Mais tarde, em casa, Mame me revelou privadamente sua insatisfação: ficou impressionado com a perfeição do molde em gesso, uma réplica perfeita de sua mão (mas destacada de seu corpo) e com a possibilidade de tê-la para sempre depositada no acervo do MAE que ele conhecera no dia anterior. Ele me perguntava: "depois da exposição, minha mão ficará para sempre ali, guardada?". Aceitei evidentemente sua insatisfação e lamentei a minha imprudência. Como não pude antes imaginar que a experiência daria errado se os corpos inertes, mortos, são assustadores? Como pude desconsiderar suas preocupações se há pouco mais de cem anos os corpos eram destruídos, queimados e se os Katukina têm temor dos cemitérios, dos locais onde se depositam corpos defuntos? (Lima 2000) Pior ainda, como não imaginei que substâncias como saliva, urina, suor e cabelo podem servir à veiculação de malefícios, podem servir à feitiçaria? Como parte de seu corpo, a réplica perfeita de sua mão poderia potencialmente servir a propósitos contraditórios aos de seu portador.

A insatisfação de Mame com o molde em gesso foi contemplada - evidentemente sequer imaginei contrariálo - e a réplica de sua mão lhe foi entregue para dar o destino que the aprouvesse. Naquele momento Mame não quis desfazer-se dela, preferiu guardá-la e levá-la para sua aldeia a fim de mostrá-la a seus parentes. Disse que a destruiria depois disso. Ensinei-lhe então que bastaria colocar a réplica na água que se desfaria toda. Surpreso, gostou dessa alternativa. Soube há pouco que a réplica ainda não foi destruída.

Como disse antes, lamentei minha imprudência, deveria saber que a efemeridade é uma marca forte não apenas dos kãchis mas da concepção de mundo dos Katukina, que estranham nossa fixação com o tempo e com a duração das coisas. Se puder resumir com simplicidade, é como se Mame e seu filho estranhassem bastante nossa obsessão com o colecionamento e com a tentativa de fazer as coisas durarem "para sempre" - uma alternativa que não lhes pareceria sequer desejável. A antiguidade das peças da RT do MAE pareceu a Mame surpreendente, não pela existência e diversidade delas em si mesmas, mas pela perenidade a que as sujeitamos. Nos museus, como bem escreveu João Pacheco de Oliveira (2007), "pessoas e entidades estão ali representadas, pois uma de suas finalidades básicas é presentificar os que estão ausentes". Mame identificou imediatamente tal ambição na $\mathrm{RT}$, mas não lhe pareceu atraente tal possibilidade. ${ }^{14}$

Agora um breve parêntese: Mame não lamentou quando viu um chomo (um pote de cerâmica, com um bojo grande e um estreito gargalo, usado para rezas) katukina na RT. Este chomo me foi dado por Kako em 2011, quando fiz uma rápida visita a campo e procurei por um exemplar, a fim de integrar a exposição permanente do MAE como um "objeto xamânico"15. Naquela ocasião, propus comprá-lo, mas meu interlocutor decidiu me dar o chomo de 
presente, claramente querendo se livrar do objeto que havia sido elaborado por sua tia, uma velha senhora que acabara de morrer. Como sei há bastante tempo, é difícil que alguém queira ficar com objetos de pessoas mortas, receando serem atraídas pela saudade para o lado dela - que já está do lado dos mortos (Lima 2000). Kako viu em meu pedido uma oportunidade de desfazer-se do objeto sem mais delongas.

Tentando refletir sobre as preocupações de Mame, não me pareceu que o chomo e a réplica de sua mão pudessem ocupar conceitualmente o mesmo lugar enquanto objetos musealizados. Possivelmente não, daí sua recusa pela guarda de sua mão na $\mathrm{RT}$ do $\mathrm{MAE}$, mas sem qualquer censura à musealização do chomo. Não deve ser demais lembrar que após a morte de uma pessoa, poucas querem acumular seus objetos e uma estratégia a qual alguns katukina recorrem, pelo menos desde os anos 80, é desfazer-se de seus pertences, mas trocando-os com brancos vizinhos, sem destruí-los efetivamente. Isso garante o afastamento das coisas do morto, e o risco que representam, e reduz ao menos em parte as perdas materiais que a morte implica e que se tornaram relativamente maiores nos dias de hoje, quando a aquisição dos objetos deve se fazer por meios monetários. Assim, atualmente desfazer-se de todos os objetos implica em um grande "prejuízo", mas os Katukina criam suas próprias formas de atenuá-los. Foi isso, por exemplo, que fez Mani, um interlocutor muito próximo, quando morreu sua filha: reuniu os objetos da falecida e foi até os brancos vizinhos oferecê-los em troca de um casal de bacorinhos. (Lima 2000)

De modo enviesado, o tema da morte apareceu de forma saliente na elaboração da exposição, particularmente na apresentação da Reserva Técnica do $M A E$, e não deve ser exagerado nem surpreendente indicar que, como pano de fundo, uma analogia se insinuava entre museus e cemitérios. E nessa analogia estava implicada a possibilidade de considerar a vida das coisas ${ }^{16}$ e de seus produtores.

O trabalho de tradução numa atividade supostamente tão amena quanto a montagem de uma exposição revelava seu desafio - e, como a compreendo, a necessária presença da antropóloga como mediadora. Era preciso ensaiar novas formas de elaborar a experiência no museu e romper com formas convencionais de imaginar práticas museológicas. Concordando com Oliveira Filho (2007), parecia-me preciso pensar em formas de "modificar a relação narcísica que museus e exposições etnográficas mantêm com os seus visitantes habituais, o grande público branco e urbano".

Restou, ao final, sem termos quaisquer experiências anteriores a nos guiar, aprender muitas coisas juntos. E a experiência que constituíamos tinha claramente implicações internas e externas. Quanto às primeiras, refirome justamente ao esforço dialógico que foi estabelecido para que a exposição se realizasse de forma a tentar conciliar as expectativas nativas, museológicas e antropológicas. Era preciso comunicar, mas sem tornar rígidas as camas-de-gato, apresentando-o como parte da vida ordinária, sem torná-los exóticos. Permitimo-nos expô-los de modo fixo, mas não fixar a forma destacada de uma parte do corpo do co-curador com o molde em gesso de suas mãos. Os arranjos que se foram produzindo supunham o desafio de fazer saliente a forma nativa - algo que espero termos alcançado, desfazendo parte da fixidez dos kãchi com o breve filme. 


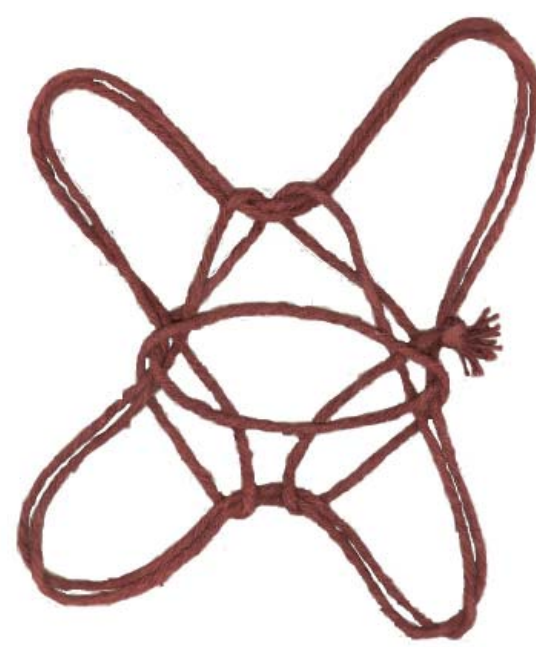

Figura 3: sem nome registrado
Quanto às implicações externas, são relativas ao público da exposição. Como expor os kãchi guardando proximidade com a perspectiva nativa, sem exoticizá-la, e contemplar o público, ou contemplar um e outro? Preocupavame particularmente a impossibilidade de apenas "mostrar" objetos, como se tratasse simplesmente de expô-los à visão. O esforço empreendido visava não apenas disponibilizar os kãchi aos olhares curiosos, mas proporcionar aos visitantes do MAE uma experiência sobre outras formas de brincar ou, particularmente, sobre a forma katukina de criar com o barbante. Uma forma, diga-se de passagem, que poderia ainda merecer estudos mais detalhados, não necessariamente de antropologia, para entender como se efetuam os cálculos que resultam naquelas formas. O vai-e-vem do barbante não é, evidentemente, aleatório e o cálculo posto em ação envolve quase sempre todos os dedos das mãos, aparando e segurando partes que serão enlaçadas, às vezes servindo-se para isso também da boca ou dos pés. Assim, ocorreme que poderia ser bastante apropriado um estudo de matemática sobre o kãchi, por exemplo, para compreender a métrica que, bem arranjada, conduz à forma final. ${ }^{17}$

O kãchi assemelha-se ligeiramente às nossas camas-de-gato, mas não mais do que isso, pois o esforço criativo revela uma diversidade de formas imensa se comparada às nossas, àquelas que sabemos realizar. A quantidade de dedos que acionamos para dar forma ao barbante é uma das marcas dessa diferença, isso sem falar na quantidade de formas que realizamos. A propósito, em nosso tour pela RT, eu e uma estudante que convidei para auxiliar nas filmagens e na edição do filme, Mariza Rodrigues, fizemos algumas camas-de-gato para mostrar a Mame a maneira como brincamos. Quando acabamos Mame laconicamente se pronunciou sobre a limitação de nosso repertório: "mas é só isso?".

Voltando à concepção da exposição, sei que minhas preocupações são familiares às de outros curadores, em diferentes áreas de conhecimento, pois não se trata apenas de dispor objetos - kãchis, no caso - à visão, mas também a uma certa percepção. Tais preocupações esparsas foram bem destacas por Bittencourt, que escreveu:

“...'ver' nem sempre é 'conhecer'. A capacidade de uma exposição em fazer o visitante entender seu conteúdo não é automática. O objeto musealizado ou em sua vida comum, não possui propriedades intrínsecas que não sejam seus aspectos físico-químicos. Adiante desses, tudo que dele se consegue extrair é sentido, é fazer significar alguma coisa. Deixemos bem claro: o objeto não fala. Quem fala, através dele, é o curador" (Bittencourt 2008:5).

Para encerrar, quero só fazer uma observação com os diferentes sentidos que podem ter as palavras e como podem se encontrar com outras coisas. Assim, durante os dias da montagem da exposição, dessa experiência tão nova para todos - para a equipe do MAE, para mim e para Mame e Wisi - fiquei pensando sobre o significado da palavra "curador", lugar que ocupamos (eu, Mame e Wisi), em nossa curadoria partilhada. 
Como sabemos, nos ambientes acadêmicos a palavra curadoria tem uma longa história, com sua origem no latim, na palavra curator, que, entre outras coisas, quer dizer "aquele que tem cuidado e apreço". Não irei me ater à construção histórica da palavra curador, a quem o faça com maior competência (Bittencourt 2008). Prefiro ater-me aqui ao sentido nativo que pode ter a palavra.

No Acre, de onde são Mame e Wisi, a palavra "curador" é mais usada, no português regional, para dizer das pessoas que se dedicam à cura, que tentam restabelecer a saúde das pessoas enfermas. Na língua katukina, os curadores são os shointya. Não resisti e fui procurar no dicionário Houaiss, que me indicou que esse é o primeiro sentido do "curador" - "aquele que cura ou sara um doente". O segundo significado é justamente aquele relacionado à "curadoria", tal como a realizamos em espaços museais. Sei bem que nenhum de nós - nem eu, nem Mame, nem Wisi - é shointya. Ainda assim, quero aproximar os dois sentidos, em português, de "curador" para dizer que espero que esse trabalho que realizamos esteja relacionado também ao ato de "curar", ligando-o ao zelo, ao cuidado, à atenção que as pequenas coisas merecem. Assim, ligo-o também ao ofício dos antropólogos - da antropóloga, neste caso. O kãchi é seguramente uma dessas pequenas coisas delicadas, que precisa ser feita e refeita continuamente para continuar a existir. Por isso mesmo, foi com grande satisfação que pude participar da realização da exposição em um Museu, especialmente no MAE/UFPR, subvertendo um tanto da dureza de suas pedras, da sua perenidade. Foi também uma experiência inédita de compartilhar o espaço museal com aqueles que dela não deveriam ter sido apartados.

Como sabemos, enquanto disciplina, a Antropologia se constituiu a partir dos museus, afastou-se deles durante parte extensa do século passado e está há certo tempo fazendo o caminho de volta. A boa notícia, no contexto pós-colonial, é que estamos retomando o caminho acompanhados dos nossos interlocutores, feito amigos durante temporadas de trabalho de campo, em atividades de pesquisa. Inevitável dizer que neste percurso, ambos, pesquisadores e nativos, acabam mutuamente conhecendo-se um tanto mais, e vivendo, sem artifícios, aquilo que Fabian (2013) definiu como alguma coetaneidade. 


\section{NOTAS}

1 Trata-se de uma versão ligeiramente ampliada da comunicação apresentada na Mesa Redonda Experiência e Reflexões sobre Curadoria Compartilhada, no I Seminário de Etnologia e Museus, promovido pelo MAE e pelo PPGA da UFPR, em Curitiba, em 27 de agosto de 2015. Dois meses depois, a mesma comunicação foi apresentada no II Colóquio de Antropologia da UFMT. Agradeço aqui a todos os colegas e alunos que se engajaram na realização da exposição. Em Curitiba, correndo o risco de esquecer de alguém, destaco: Márcia Rosato, Laura Pérez Gil, Ana Luísa Mello, Douglas Fróis, João Kalluf, Marisa Rodrigues, Mariana Zarpellon e Ramiro Garcia. Na logística acreana, com as facilitações para que Mame e Wisi chegassem a Curitiba, Dedê Maia, Marcelo Piedrafita Iglesias, Ariel Carvalho e João Santos ofereceram um suporte imprescindível.

2 A exposição Kãchi foi a mais visitada no MAE no ano de 2015, totalizando 32.498 visitantes, entre o público local (alunos de escola pública, principalmente) e o espontâneo, conforme me informou Márcia Rosato, diretora do Museu (informação pessoal 2016).

3 Mame tem pouco mais de 40 anos e foi durante vários anos professor do ensino fundamental da escola da Terra Indígena em que mora desde meados de 1990, no momento está aposentado por invalidez, em virtude de um acidente ofídico que resultou na amputação de parte de sua perna esquerda. Seu filho, Wisi, tem 18 anos e cursa atualmente o ensino médio.

4 Faço tal observação tendo em conta as previsíveis e inevitáveis negociações para a realização de pesquisa de campo no contexto contemporâneo. Embora em outro momento tenha ocorrido desentendimentos entre mim e algumas das lideranças katukina, como exposto em Lima (2014), na realização da exposição não ocorreram quaisquer contestações.

5 Agradeço a João Dal Poz por ter me indicado tal referência.

6 Conforme http://pibmirim.socioambiental.org/como-vivem/brincadeiras/, consultado em 21 de julho de 2015

7 Conforme consta (Averkieva \& Sherman 1992: xiii), Boas foi o primeiro a registrar os jogos de fio entre os Esquimós, em 1888. Cabe mencionar que a co-autora do livro indicado, Julia Averkieva, de origem russa, em 1930, acompanhou Boas em pesquisa de campo na Colúmbia Britânica.

8 Entre outros grupos indígenas ao redor do mundo a realização dos jogos de fio se faz também entrelaçada a concepções míticas e religiosas, cf. Averkieva e Sherman (1992).

9 Trata-se de um filme - Kãchi Katukina - de curta duração, são aproximadamente seis minutos, em que Mame e Wisi mostram como realizam quatro kãchi, no pátio do prédio histórico do MAE, em Paranaguá. O filme foi concebido para acompanhar a exposição. Fora dela é possível visualizá-lo a partir de https://www.youtube.com/watch?v=kTpoQDpFcHU

10 O shevi não foi exposto no filme, mas existe a filmagem de sua realização por Wisi. As imagens compõem agora o acervo do MAE.

11 Estive pela primeira vez entre os Katukina da TI do rio Campinas em 1991 e de lá para cá passei mais de vinte meses em campo, a maior parte na década de 1990.

12 Inicialmente pensamos que Rai, quem primeiro me apresentou o kãchi, é quem deveria acompanhar Mame até Curitiba. Infelizmente ele acabou não podendo vir, dado que foi contratado como professor pela Secretaria de Educação do governo do Acre e não poderia se ausentar da sala de aula, o que explica a substituição dele por Wisi.

13 Todo nosso tour pela Reserva Técnico do MAE foi documentado pela equipe do MAE, e também por Wisi que fotografava os objetos e pessoas que conhecia na ocasião com seu aparelho de telefone celular.

14 Cabe aqui destacar que na primeira vez que apresentei essa comunicação, no I Seminário de Etnologia Museus, na UFPR, em agosto de 2015, mais de um colega me questionou sobre o fato de Mame ter uma perna amputada e que a réplica de sua mão - essa parte destaca de seu corpo, como afirmei - poderia remeter à sua condição física. Não desconsidero essa possibilidade, apenas destaco que ela não me foi em nenhum momento sugerida por Mame, que parecia mais preocupado com a perenidade dos objetos na RT. Tentar explorar essa possibilidade interpretativa exigiria de mim contradizer ou recusar a interpretação do próprio Mame, uma alternativa que me pareceu inadequada dada a espontaneidade de nosso diálogo que busco registrar aqui. 
15 O modelo do chomo katukina é bastante parecido com o dos Marubo (ver Montagner Melatti 1977). O mesmo objeto é encontrado em outros grupos de língua pano, sempre vinculado a propósitos xamânicos. Entre os Shipibo-Conibo, Illius (1994) definiu o chomo como um "microcosmos modelo".

16 Torna-se aqui inevitável lembrar das observações de Martini (2012) sobre a repatriação dos ornamentos de povos rionegrinos, que gerou intensa discussão. Enquanto alguns argumentavam que os ornamentos repatriados estavam mortos devido à longa ausência da vida cerimonial, lideranças políticas insistiam em dispô-los em lauaretê e fazê-los retornar à vida. O temor que objetos despertaram revelou-se fortemente na recepção em lauaretê, quando poucos se dispuseram a acompanhar a chegada dos ornamentos.

17 Após a montagem da exposição, já na redação final deste artigo, deparei-me um estudo em etnomatemática sobre as camas-de-gato dos trobriandeses, recentemente publicado por Valendriessche (2014), e entusiasmei-me ao imaginar que algum matemático poderia se interessar por aquelas feitas pelos Katukina. Soube também que há uma Associação que reúne os aficionados pelos jogos de barbante. Trata-se da Internation String Figure Association (ISFA), fundada em 1978 por um matemático japonês e um missionário anglicano radicado na Papua Nova Guiné, conforme consta do sítio eletrônico http://www.isfa.org/isfa2.htm, consultado em 09 de dezembro de 2015. Um tempo depois, no final de 2016, encontrei-me com o professor e físico Ennio Candotti, após uma palestra em Curitiba em que abordava justamente a simetria nas formas elaboradas em grafismos indígenas. Conversei brevemente com Candotti sobre as camas-de-gato dos Katukina que então me indicou que a teoria dos nós poderia ajudar a compreender o entrelaçar dos fios, mas sem auto intersecções, permitindo que os enlaçamentos sempre se desfaçam sem formar emaranhados. Dados meus parcos conhecimentos matemáticos, apenas registro a sugestão de Candotti àqueles mais versados que possam interessar-se pelo assunto. 


\section{REFERÊNCIAS BIBLIOGRÁFICAS}

AVERKIEVA, Julia \& SHERMAN, Mark A. 1992. Kwakiut/ String Figures. Seattle / London / New York: University of Washington Press/American Museum of Natural History.

BITTENCOURT, José Neves. 2008. “Mediação, curadoria, museu. Uma introdução em torno de definições, intenções e atores" In Cadernos de Diretrizes Museológicas 2. Belo Horizonte: Secretaria de Estado da Cultura, Superintendência de Museus.

FABIAN, Johannes. 2013. O tempo e o outro. Como a antropologia estabelece seu objeto. Petrópolis: Vozes.

GALLOIS, Dominique. 1994. Mairi revisitada. A reintegração da Fortaleza de Macapá na tradição oral dos Waiãpi. São Paulo: NHII/USP/FAPESP.

GUEVARA, Ana. 2011. "De madre a hija: juegos de hilo y memoria(s) del paisaje mapuche". Corpus. Archivos virtuales de la alteridad americana 1(1). Disponível em: http://ppct.caicyt.gov.ar/index.php/corpus/article/view/285/97

ILLIUS, Bruno. 1994. “La 'gran boa'. Arte y cosmologia de los Shipibo-Conibo". Amazonía Peruana XII(24): $185-212$.

KERSTEN, Márcia Scholtz. 2000. Os rituais do tombamento e a escrita da história. Curitiba: Editora da UFPR.

KOCH-GRÜMBERG, Theodor. 2005. Dois anos entre os indígenas. Viagens no noroeste do Brasil (1902-1905). Manaus: EDUA/FSDB.

LIMA, Edilene Coffaci. 2000. Com os olhos da serpente. Tese de Doutorado. São Paulo: USP.

2012. "A gente é que sabe ou sobre as coisas katukina (pano)". Revista de Antropologia 55 (1): $139-169$.

2014. "'Nosso conhecimento vale ouro': sobre o valor do trabalho de campo". Anuário Antropológico 39 (1): $73-98$.

MARTÍNEZ CASTELLOTE, Ramón. 1996. Juegos de los indios norteamericanos para jugar en la naturaleza. Madri: Miragrano ediciones.

MARTINI, André. 2012. “O retorno dos mortos: apontamentos sobre a repatriação de ornamentos de dança (busá, busá) do Museu do Índio, em Manaus, para o rio Negro". Revista de Antropologia 55 (1): 331-356.

MONTAGNER MELATTI, Delvair. 1977. “Cerâmica marubo". Cultura 25: 70-77.

OLIVEIRA FILHO, João Pacheco. 2007. “O retrato de um menino bororo: narrativa sobre o destino dos índios e o horizonte político dos museus, séculos XIX e XX". Tempo, Revista digital do Programa de Pós-Graduação em História da UFF 12(23). Disponível em http://www.scielo.br/pdf/tem/v12n23/v12n23a06 .

SHERMAN, Mark. A. 1992. "Introduction by Mark A. Sherman”. In J. Averkieva, \& Mark A. Sherman. Kwakiut/ String Figures. Seattle / London / New York: University of Washington Press/American Museum of Natural History.

VALENDRIESSCHE, Eric. 2014. “Ethnomathématique des jeux de ficelles trobriandais”. Ethnographiques.org 29. Disponível em http://www.ethnographiques.org/Ethnomathematique-des-jeux-de,1058, Acesso em 09/12/2015.

VICTOR, Paul-Émile. 1937. “Les jeux de ficelle chez les Eskimo d'Angmagssalik”. Journal de la Société des Américanistes 29 (2): 387-395.

VIDAURRÁZAGA, Tamara. 2012. “Ka tere te vaka. Kai kai rapanui. Una aproximación crítica a su clasificación como juego". Amerika [on line] 6. Disponível em http://amerika.revues.org/2988. Acesso em: 07/12/2015. 


\section{O kãchi no MAE/UFPR: sobre uma experiência de curadoria compartilhada}

\section{RESUMO}

Apresento neste artigo os diálogos e negociações que tiveram lugar entre os curadores durante a concepção e realização da exposição Kãchi, realizada no Museu de Etnologia e Arqueologia da Universidade Federal do Paraná (MAE/UFPR). Montada a partir de uma curadoria compartilhada que reuniu a autora e dois katukina, a exposição buscou apresentar os jogos de barbante (ou camas-de-gato) que conheceu durante seu trabalho de campo na década de 1990.

PALAVRAS-CHAVE: camas-de-gato; katukina; curadoria; museu

\section{The Kãchi in the MAE / UFPR: on a shared curatorial experience}

\section{ABSTRACT}

In this article, I presents the dialogues and negotiations that took place between the curators during the design and construction of exhibition called Kãchi, held at the Museum of Ethnology and Archaeology at the Federal University of Paraná (MAE / UFPR). Assembled from a shared curatorial attended by the author and two Katukina, the exhibition aimed to present the string figures that she knew during her fieldwork in the 1990s.

KEYWORDS: string figures; katukina; curator; museum 